\title{
Tamoxifen-inducible cardiac-specific Cre transgenic mouse using VIPR2 intron
}

\author{
Hyun Jung Chin, So-young Lee and Daekee Lee* (D)
}

\begin{abstract}
Genetically engineered mouse models through gene deletion are useful tools for analyzing gene function. To delete a gene in a certain tissue temporally, tissue-specific and tamoxifen-inducible Cre transgenic mice are generally used. Here, we generated transgenic mouse with cardiac-specific expression of Cre recombinase fused to a mutant estrogen ligand-binding domain (ERT2) on both N-terminal and C-terminal under the regulatory region of human vasoactive intestinal peptide receptor 2 (VIPR2) intron and Hsp68 promoter (VIPR2-ERT2CreERT2). In VIPR2ERT2CreERT2 transgenic mice, mRNA for Cre gene was highly expressed in the heart. To further reveal heart-specific Cre expression, VIPR2-ERT2CreERT2 mice mated with ROSA26-lacZ reporter mice were examined by X-gal staining. Results of X-gal staining revealed that Cre-dependent recombination occurred only in the heart after treatment with tamoxifen. Taken together, these results demonstrate that VIPR2-ERT2CreERT2 transgenic mouse is a useful model to unveil a specific gene function in the heart.
\end{abstract}

Keywords: VIPR2 intron, ERT2CreERT2, Heart, Tamoxifen-inducible Cre transgenic mouse

\section{Introduction}

The heart is the first organ to develop. It is also the most important organ for survival during embryonic development [1]. Gene knockout experiments have shown that abnormal development of the heart is the main cause of embryonic lethality [2], making it difficult to study specific gene function in the adult heart. To resolve this limitation, Cre/loxP recombination system has been developed to examine gene functions through gene deletion using adult mice $[3,4]$. Such $\mathrm{Cre} /$ loxP-mediated conditional gene targeting can be used to study tissue-specific gene function, including genes expressed in the heart [5]. To activate Cre in a spatiotemporal manner, tamoxifen-inducible Cre/loxP recombination system requires Cre recombinase fused with a mutant form of estrogen receptor (CreERT2) which can migrate to the nucleus and induce sitespecific recombination after treatment with tamoxifen

\footnotetext{
* Correspondence: daekee@ewha.ac.kr

Department of Life Science, Ewha Womans University, Ewhayeodae-gil 52, Seodaemun-gu, Seoul 03760, South Korea
}

[6]. Leaky Cre recombinase activity irrelevant to tamoxifen treatment can be more tightly controlled by placing the mutant estrogen receptor to both ends of Cre protein such as MerCreMer [7] and ERT2CreERT2 [8].

Regulatory DNA sequences are essential to achieve specific Cre expression. However, most Cre mouse lines express $\mathrm{Cre}$ in more than one specific tissue, leading to misinterpretation of data due to indirect effect of Cre-mediated gene deletion in other tissues on overall phenotype. In the present study, we selected an enhancer for heart-specific gene expression using VISTA enhancer browser and experimentally tested enhancer activity in transgenic mice [9]. Among these enhancers, hs1753 located in intron 4 of human VIPR2 gene exhibited LacZ expression only in the heart, not in other region of embryonic day 11.5 (E11.5) mouse embryos. We generated a tamoxifeninducible Cre transgenic mice using VIPR2-ERT2CreERT2 expression vector consisting of hs1753 regulatory sequence, Hsp68 promoter, ERT2CreERT2 cDNA, and the

(c) The Author(s). 2020 Open Access This article is licensed under a Creative Commons Attribution 4.0 International License, which permits use, sharing, adaptation, distribution and reproduction in any medium or format, as long as you give appropriate credit to the original author(s) and the source, provide a link to the Creative Commons licence, and indicate if changes were made. The images or other third party material in this article are included in the article's Creative Commons licence, unless indicated otherwise in a credit line to the material. If material is not included in the article's Creative Commons licence and your intended use is not permitted by statutory regulation or exceeds the permitted use, you will need to obtain permission directly from the copyright holder. To view a copy of this licence, visit http://creativecommons.org/licenses/by/4.0/ The Creative Commons Public Domain Dedication waiver (http://creativecommons.org/publicdomain/zero/1.0/) applies to the data made available in this article, unless otherwise stated in a credit line to the data. 
polyadenylation site from the SV40 early region. We investigated whether Cre-dependent recombination occurs only in the heart of the embryo or adult after tamoxifen treatment on mice born by further crossing the VIPR2ERT2CreERT2 transgenic mouse with the ROSA26-lacZ reporter mouse.

\section{Materials and methods}

Construction of VIPR2-ERT2CreERT2 expression vector Plasmid $p C A G-E R T 2 C r e E R T 2$ was a gift from Connie Cepko (Addgene plasmid \# 13777). pHsp68-LacZGateway was a gift from Nadav Ahituv (Addgene plasmid \# 37843) and the plasmid $p C r e-E R T 2$ was a gift from Pierre Chambon. All restriction enzymes and Phusion ${ }^{\circ}$ high-fidelity DNA polymerase for PCR amplification were purchased from NEB (Ipswich, MA, USA). EcoR1-SacI fragment $(2.0 \mathrm{~kb})$ and SacISalI $(0.17 \mathrm{~kb})$ fragment of $p C r e-E R T 2$ were cloned to EcoR1 and SalI sites of pBluescript II SK(+) to generate $p C r e-E R T 2 p A$ vector. A SmaI-ClaI fragment (1.8 $\mathrm{kb})$ of $p C A G-E R T 2 C r e E R T 2$ was further cloned to SmaI and ClaI sites of $p C r e-E R T 2 p A$ to generate $p E R T 2 C r e E R T 2 p A$ vector without promoter or enhancer. Finally, VIPR2-driven ERT2CreERT2 expression vector ( $p$ VIPR2-ERT2CreERT2pA) was constructed as follows. Human VIPR2 genomic DNA located in intron 4 was amplified by PCR using a BAC clone (RP11-645 K21, BACPAC Resources, Oakland, CA, USA) with sense primer (5'-AAGCGGCCGCTGGGAGGAGA AGGGCTCTGC-3', NotI site underlined) and antisense primer $\quad\left(5^{\prime}\right.$-TTGACGCGTGAGAACAGGAGTGTCAC CGG-3'; MluI site underlined). The PCR product (3.0 kb) was digested with $N o t \mathrm{I}$ and $M l u \mathrm{I}$ followed by purification with QIAquick PCR purification kit (Qiagen, Germany). The minimal promoter sequence of $\mathrm{Hsp} 68$ was amplified by PCR using a pHsp68-LacZ-Gateway (Ref: PubMed 17086198) with sense primer (5'- TTGACG CGTGAGCTTCCAGGAACATCCAAA-3', MluI site underlined) and antisense primer (5'-AATCTAGACG CTCTGCTTCTGGAAGGCT-3', XbaI site underlined). The PCR product $(0.9 \mathrm{~kb})$ was digested with $M l u \mathrm{I}$ and $X b a \mathrm{I}$ followed by purification with QIAquick PCR purification kit. Both fragments were cloned to NotI and SpeI sites of $p E R T 2 C r e E R T 2 p A$ to obtain $p$ VIPR2ERT2CreERT2pA. 5' VIPR2 sequence of $p$ VIPR2-ERT2CreERT2pA was verified by DNA sequencing. NotI-KpnI fragment of VIPR2-ERT2CreERT2 expression vector was purified with QIAquick gel extraction kit (Qiagen) and dissolved in TE buffer (10 mM Tris- $\mathrm{HCl}, \mathrm{pH} 7.4,0.25 \mathrm{mM}$ EDTA) to $1 \mu \mathrm{g} / \mathrm{ml}$ for microinjection.

\section{Generation and maintenance of transgenic mice}

Three-week-old female FVB/N mice were injected intraperitoneally with pregnant mare serum gonadotropin
(Merck KGaA, Germany) and human chorionic gonadotropin (hCG, Merck KGaA) $48 \mathrm{~h}$ later. After administration of hCG, female mice were mated with $\mathrm{FVB} / \mathrm{N}$ male mice. The ampulla region of oviduct from plugged females was teared with a fine needle in $1 \mathrm{x}$ PBS containing $0.1 \%$ hyaluronidase (Merck $\mathrm{KGaA}$ ) and $0.1 \%$ polyvinylpyrrolidone (M.W. $40 \mathrm{kDa}$, Merck KGaA). Fertilized eggs were collected using mouth-controlled pipet. These eggs were washed several times with M2 medium (Merck KGaA) and cultured in the drop of KSOM medium (Merck $\mathrm{KGaA}$ ) under mineral oil (Merck KGaA) until microinjection. After pronuclear injection of DNA, eggs survived microinjection were then transferred into oviducts of pseudopregnant ICR females. Founder mice containing injection gene were identified with PCR genotyping. Subsequent generation of transgenic mice were maintained congenic on $\mathrm{C} 57 \mathrm{BL} / 6 \mathrm{~J}$ genetic background. All mice experiments were approved by the Institutional Animal Care and Use Committee (IACUC) of Ewha Womans University (Permit number: 2015-01-072).

\section{PCR genotyping}

Toe clips from 7 to 10 days old pups were used to extract DNA for PCR genotyping with 4 primers. PCR primers Hsp68-S1 (5'-CAGGTCACCAGACGCTGACA-3') and ERT2-AS1 (5'-TCATGTCTCCAGCCATGGTG-3') produced a 276-bp PCR product specific for transgene while PCR primers Ereg-S3 and Ereg-AS1 primers produced a 159-bp PCR product from Ereg gene for endogenous control [10]. PCR product was resolved with $1.2 \%$ agarose gel electrophoresis and visualized with ethidium bromide staining.

\section{RNA preparation, reverse-transcription (RT), and quantitative RT-PCR (qRT-PCR)}

After euthanasia of mouse with $\mathrm{CO}_{2}$, tissues were isolated and immediately frozen in liquid nitrogen. Total RNA was prepared using TRIzol Reagent (Thermo Fisher Scientific, Waltham, MA, USA) following the manufacturer's protocol. To remove any residual DNA in RNA preparation, RNA solution was treated with DNaseI (Thermo Fisher Scientific) at $37^{\circ} \mathrm{C}$ for $30 \mathrm{~min}$ and followed by RNA clean up with RNeasy MinElute Cleanup Kit (Qiagen, Germany). Then cDNA was generated from RNA using Superscript III reverse transcriptase (Thermo Fisher Scientific) and random hexamers as described previously [10]. Reverse transcription products were amplified by real-time PCR with $\mathrm{Cre}$-S (5'-GGCATGGTGCAAGTTGAAT-3') and Cre-AS (5' -AGCATTGCTGTCACTTGGTC-3'); Il6-S (5'-ATGAGAAAAGAGTTGTGCAATGGC-3') and Il6-AS (5' -CCAGGTAGCTATGGTACTCCAGAA-3'); 
Col3a1-S (5' -GATGAGCTTTGTGCAAAGTGG-3') and Col3a1-AS (5' -CGCAAAGGACAGATCCTGA-3') primers. $18 S$ rRNA-S (5'-TCAACTTTCGATGGTAGT CGCC-3') and $18 S$ rRNA-AS (5'-GGCCTCGAAA GAGTCCTGTATTGT-3') primers were used to determine expression level of $18 S$ rRNA as endogenous control. Real-time PCR was performed with KAPA SYBR FAST ABI Prism qPCR Kit (KAPA Biosystems, Wilmington,
MA, USA) using ABI Prism 7300 (Thermo Fisher Scientific) machine. The relative amount of transcript was quantified as described previously [11].

\section{Tamoxifen treatment}

Tamoxifen (Merck KGaA) was dissolved in ethanol to $100 \mathrm{mg} / \mathrm{ml}$ or $200 \mathrm{mg} / \mathrm{ml}$ and further diluted with sunflower seed oil (Merck KGaA) to $10 \mathrm{mg} / \mathrm{ml}$ and

\section{A}

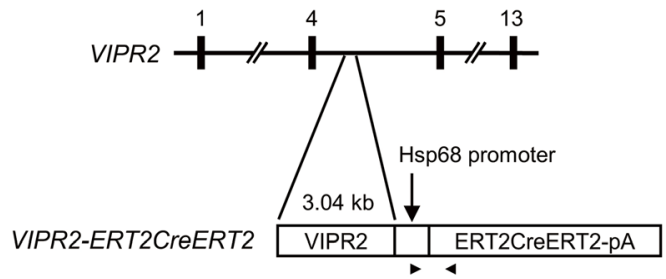

B

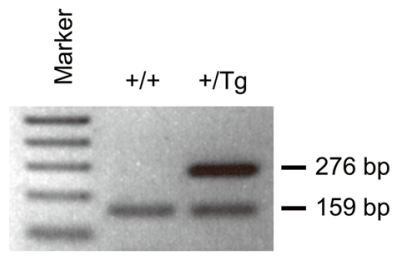

C

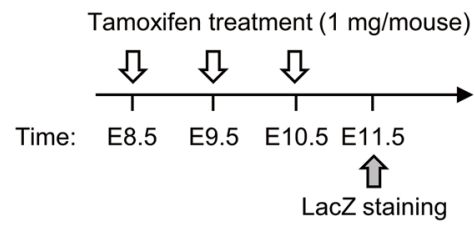

Tamoxifen treatment $(1 \mathrm{mg} /$ mouse)

LacZ staining
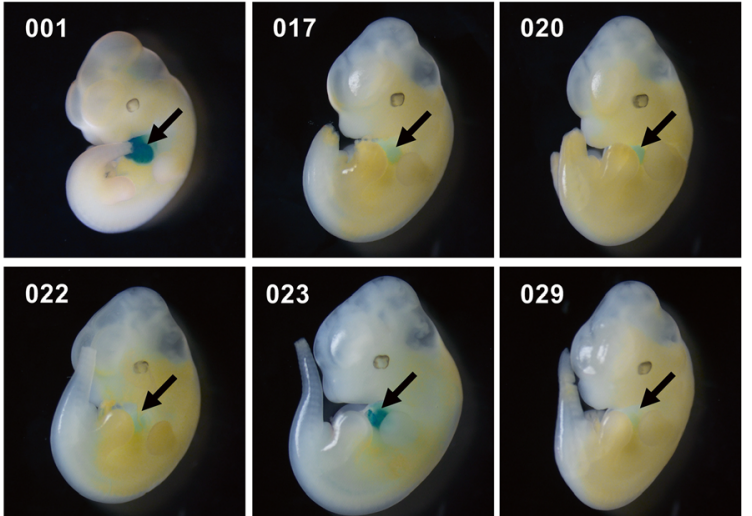

023
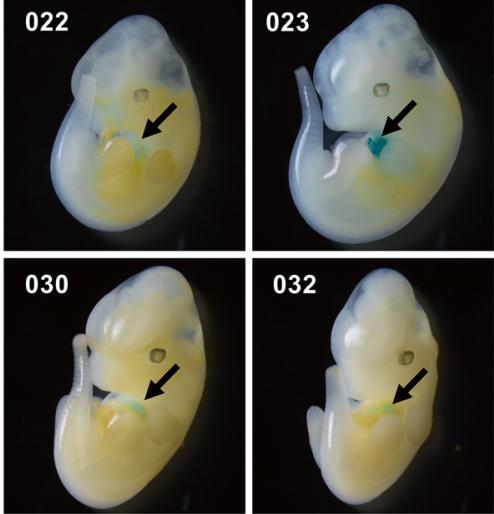

029
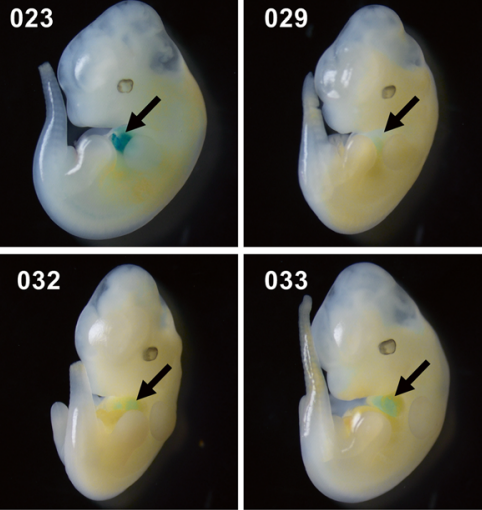

Fig. 1 Generation of VIPR2-ERT2CreERT2 transgenic mice and analysis of transgene expression. a Schematic structure of VIPR2-ERT2CreERT2 transgene. Numbers indicate exons of human VIPR2 gene. Arrowheads indicate primers for genotyping. $\mathbf{b}$ PCR genotyping of representative founder mice showing a 276-bp PCR product specific for transgene and a 159-bp product for endogenous gene $(+/+$, wild-type; $+/ \mathrm{Tg}$, heterozygous transgenic mouse). c Strategies for treating pregnant mice with tamoxifen followed by LacZ staining. $\mathbf{d}$ Whole-mount LacZ staining of VIPR2:R26 compound heterozygotes E11.5 embryos. Each number indicates VIPR2-ERT2CreERT2 transgenic mouse line. Arrows indicate heartspecific X-gal staining. Original magnification, $20 \times$ 
$20 \mathrm{mg} / \mathrm{ml}$, respectively [12]. For collection of embryos, pregnant mice at 9 days post coitum were injected intraperitoneally with $0.1 \mathrm{ml}$ of $10 \mathrm{mg} / \mathrm{ml}$ tamoxifen solution for three consecutive days. Embryos were harvested at 1 day or 3 days after the last injection. For collection of adult tissues, mice (3 to 5 months old) were injected intraperitoneally with $0.1 \mathrm{ml}$ of $20 \mathrm{mg} / \mathrm{ml}$ tamoxifen for five consecutive days and tissues were harvested at 7 days after the final injection. Ethanol in sunflower seed oil at identical concentration was injected intraperitoneally as a negative control.

\section{LacZ staining}

Embryos were collected from pregnant Gtrosa26 ${ }^{\text {tm1- }}$ Sor/tmiSor females mated with VIPR2-ERT2CreERT2 males and stained with $\mathrm{X}$-gal as described previously [13]. Whole-mount embryos were imaged using a SMZ 1000 dissecting microscope (Nikon). Tissues from adult mice derived from breeding Gtrosa26 $6^{\text {tm1- }}$ Sor/tm1Sor females with VIPR2-ERT2CreERT2 ${ }^{T g /+}$ males were collected, fixed, and stained with X-gal as described previously [10]. Slides were analyzed using a Nikon Eclipse 80i microscope and images were captured with a DS-Ri1 camera (Nikon).

\section{Statistical analysis}

Experimental groups were compared with one-way ANOVA with Turkey's multiple comparison test using GraphPad Prism program (GraphPad Software, San Diego, CA, USA).

\section{Results and discussion}

Tamoxifen-dependent Cre activity in embryonic heart of transgenic mice

VISTA enhancer browser was used to identify enhancer for heart-specific gene expression [9]. Based on LacZ staining of E11.5 embryos (https://enhancer.lbl.gov), hs1753 (chr7: $158,888,320-158,891,362$ ) located in intron 4 of human VIPR2 gene was subcloned into Hsp 68 promoter fused with ERT2CreERT2-pA to generate VIPR2-ERT2CreERT2 expression vector (Fig. 1a). A total of nine transgenic founders were obtained out of 22 newborn pups. Subsequent generations of transgenic mice were identified by PCR genotyping (Fig. 1b). To determine Cre expression, transgenic males mated with homozygous Gtrosa26 ${ }^{\text {tm1Sor }}$ [14] females were examined for the expression of LacZ due to excision of Gtrosa $26^{\text {tm } 1 \text { Sor }}$ by tamoxifen-dependent Cre recombinase. After three consecutive injections of tamoxifen, whole embryos were stained with X-gal (Fig. 1c). All transgenic lines showed heart-specific LacZ staining only in VIPR2-ERT2CreERT2 $2^{T g /+}$ and

A

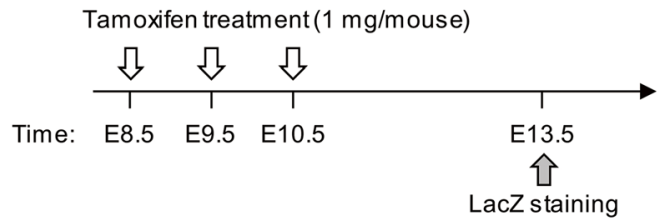

B
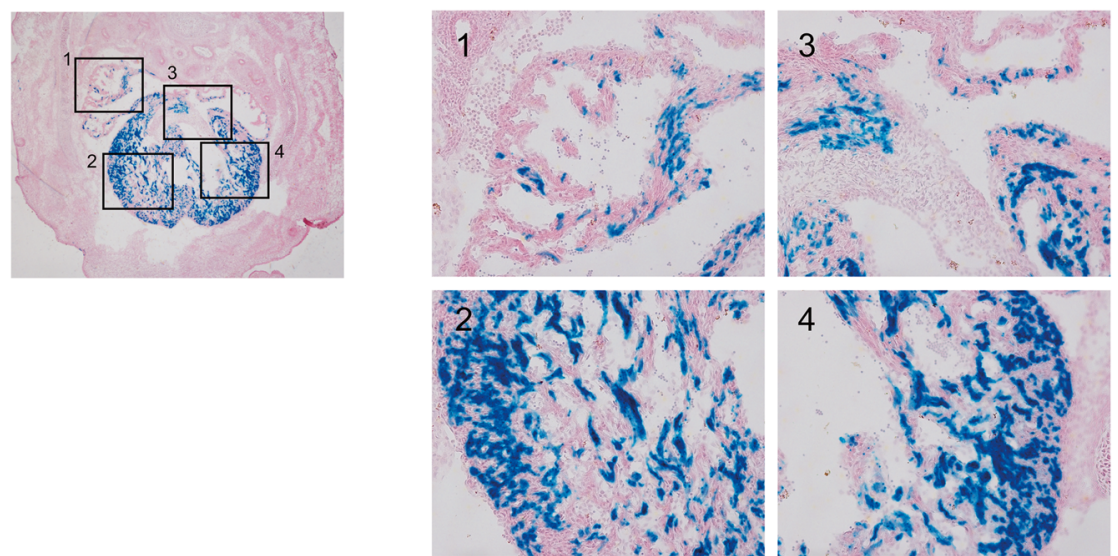

Fig. 2 LacZ staining of E13.5 embryos. a Strategies for treating pregnant mice (Gtrosa26 ${ }^{\text {tm1Sor/tmisor }}$ mated with VIPR2-ERT2CreERT2 ${ }^{\text {Tg/ }+}$ ) with tamoxifen followed by LacZ staining. b Frozen section was stained with $X$-gal followed by counterstaining with hematoxylin and eosin $Y$ (H\&E) briefly. Left, original magnification, 40x; Right, 100x magnification of rectangle 1 to 4 . Scale bar, $50 \mu \mathrm{m}$ 
Gtrosa26 ${ }^{\text {tm1Sor/+ }}$ compound heterozygous (VIPR2:R26) embryos (Fig. 1d). Because VIPR2-ERT2CreERT2-001 line exhibited the strongest expression of LacZ, further studies were performed with this line as a representative. To confirm the specificity of Cre recombination in the heart, we analyzed VIPR2:R26 E13.5 embryo sections after treating pregnant mice with tamoxifen (Fig. 2a). Heartspecific LacZ expression was detected in the whole region of the heart with punctate pattern (Fig. 2b). These results indicate that the 3.04-kb of VIPR2 intron 4 harbors cisregulatory elements for heart-specific expression during embryonic development.

\section{Heart-specific Cre activity in adult VIPR2-ERT2CreERT2 transgenic mice}

Before analyzing LacZ activity in adult VIPR2:R26 mouse, we determined Cre mRNA levels in various organs of VIPR2-ERT2CreERT2-001 line. Relative expression levels of Cre mRNA were basal in most organs compared to those in the heart (Fig. 3a). To further confirm tamoxifen induced Cre recombination, VIPR2:R26 adult mice were treated with either $2 \mathrm{mg}$ of tamoxifen or the same volume of ethanol with sunflower oil mixture $(1: 9, \mathrm{v} / \mathrm{v})$ as control injection for five consecutive days. Organs were harvested 7 days after the last injection (Fig. 3b). LacZ staining was detected mainly in cardiomyocytes of all regions with punctate pattern similar to that in the embryo (Fig. 3c). In contrast, LacZ staining was not observed in the heart of VIPR2:R26 adult mouse treated with solvent alone or Gtrosa26 ${ }^{\text {tm1Sor/+ }}$ mouse treated with tamoxifen solution (Fig. 4a, b). The heart was the only organ stained with X-gal while all other organs were negative for the X-gal staining (Fig. 4c to p). The degree of X-gal staining of the heart did not differ by gender. Moreover, consecutive treatment of VIPR2-ERT2CreERT2 transgenic mouse with tamoxifen did not show harmful effects such as inflammatory response or heart reorganization (Fig. 5a to c). Overall, these results indicate that VIPR2-ERT2CreERT2 transgenic mouse is useful for heart-specific gene knockout experiment using adult mice without leaky expression or adverse effect.

The adult heart is composed of several cell types, including cardiomyocytes, cardiac fibroblasts, vascular smooth muscle cells, and endothelial cells. Fluorescence-
A

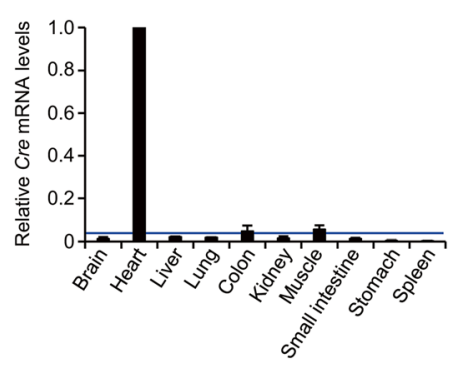

B
C

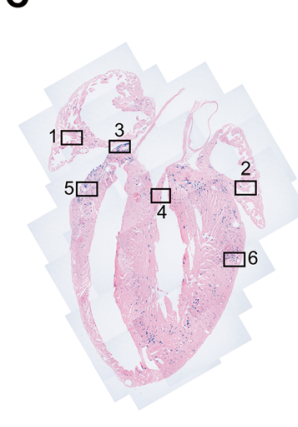

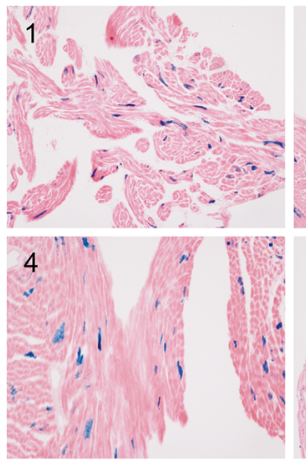

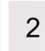

2
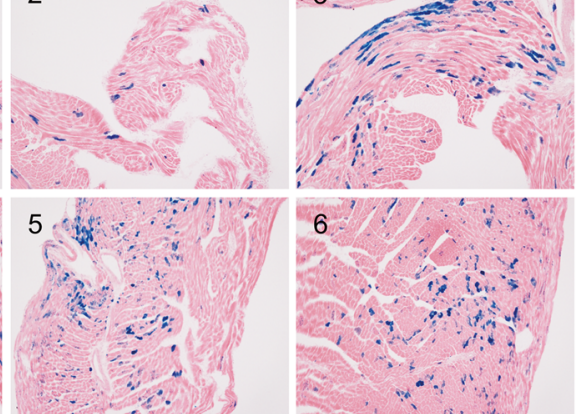

Fig. 3 Analysis of tissue-specific Cre activity. a qRT-PCR analysis of relative Cre mRNA levels in various tissues. Total RNA prepared from VIPR2ERT2CreERT2 ${ }^{T g /+}$ adult mice was analyzed by real-time PCR and the relative Cre mRNA level in each tissue was compared to the level of the heart $(n=2)$. The blue line indicates the non-specific Cre mRNA level of' the wild-type heart. Data are presented as mean \pm SD. Only the level of the heart is statistically significant $(p<0.01)$. $\mathbf{b}$ Strategies for treating adult VIPR2:R26 compound heterozygotes with tamoxifen followed by LacZ staining. c Frozen sections of the heart were stained with X-gal followed by counterstaining with H\&E briefly. 1, right atrium; 2 and 3, left atrium; 4, aortic valve; 5, right ventricle; 6, left ventricle. Original magnification, 40x; Right, 100x magnification of rectangles 1 to 6 


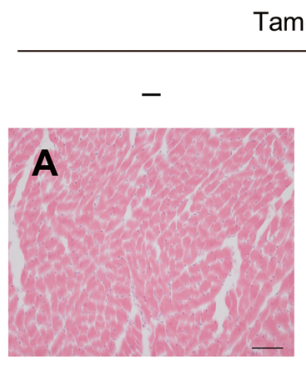

VIPR2:R26
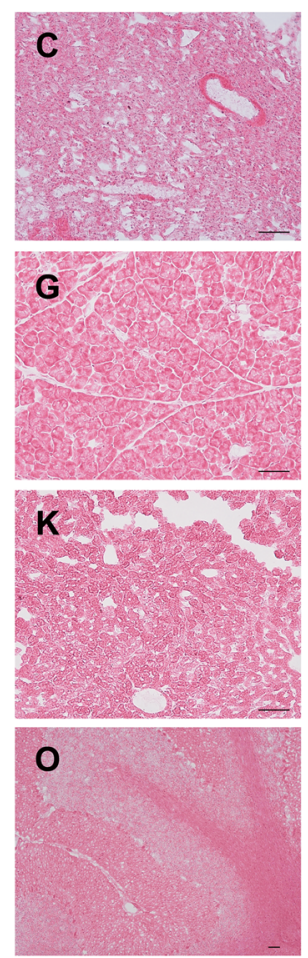
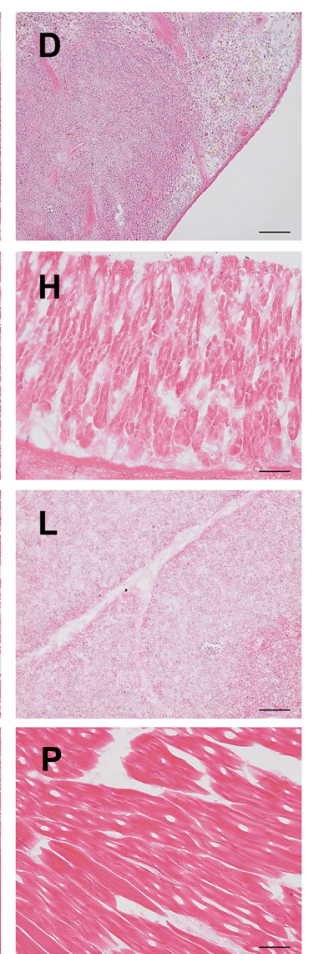
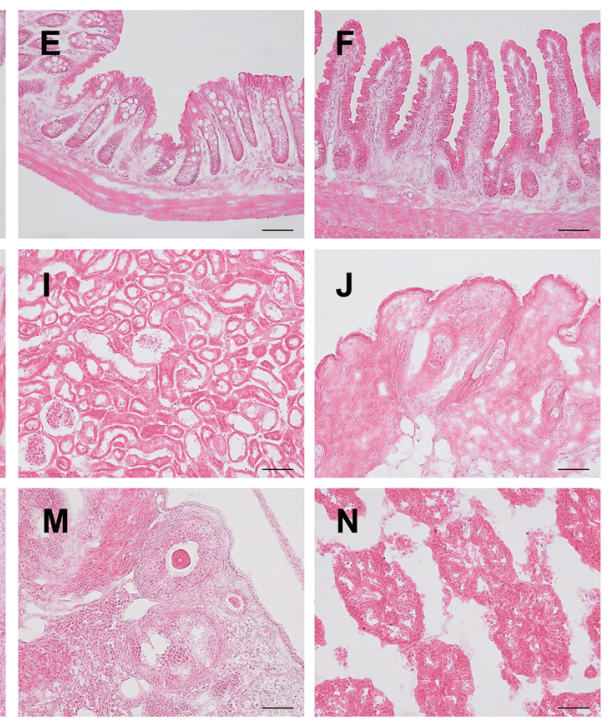

Fig. 4 Analysis of tissue-specific Cre activity by LacZ staining. Frozen sections were stained with X-gal followed by counterstaining with H\&E briefly. a Heart section of adult VIPR2:R26 compound heterozygote mouse without tamoxifen treatment. $\mathbf{b}$ Heart section of adult Gtrosa26 ${ }^{\text {tmisor/ }+}$ treated with tamoxifen; c-p Adult VIPR2:R26 compound heterozygote mouse treated with tamoxifen: c Lung; d Spleen; e Colon; f Small intestine; g Pancreas; h Stomach; i Kidney; j Skin; k Liver; I Thymus; m Ovary; n Testis; o Brain; p Muscle. Scale bar, $50 \mu$ m

activated cell sorting (FACS) analysis has revealed that cardiomyocytes, the majority of cell types, account for $56 \%$ of heart cell types while the rest of heart cells are cardiac fibroblasts (27\%), vascular smooth muscle cells (10\%), and endothelial cells (7\%) [15]. In the present study, cardiomyocytes were the major cell types for expressing LacZ while vascular smooth muscle cells and endothelial cells were rare in the heart of transgenic mice. The most widely used gene for driving heartspecific Cre expression is $\alpha$-myosin heavy chain (Myh6) [16]. Inducible Cre recombinase using Myh6 promoter has also been established $[17,18]$. However, adverse effect of tamoxifen treatment on normal heart function in
Myh6-MerCreMer mice requires appropriate control mice to avoid misinterpretation of conditional knockout mice phenotype [19, 20]. Recently developed Cre knock-in mouse by targeting a MerCreMer cassette into the start codon of Myh6 seems to be able to replace Myh6-MerCreMer mice since these knock-in mice exhibit normal heart function regardless of tamoxifen treatment [21]. In contrast to robust recombination in cardiomyocytes of $M y h 6$ promoter-driven Cre lines, VIPR2-ERT2CreERT2 transgenic mouse exhibited far less recombination in the heart, suggesting that this transgenic mouse could be useful for analyzing genes whose cardiomyocytes-wide deletion might lead to heart failure. 
A

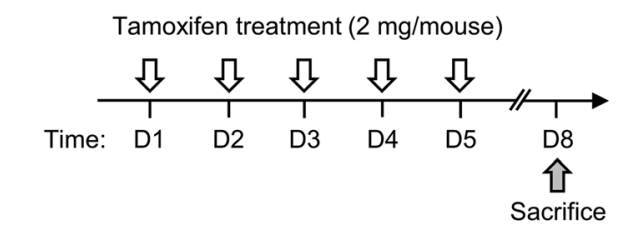

B
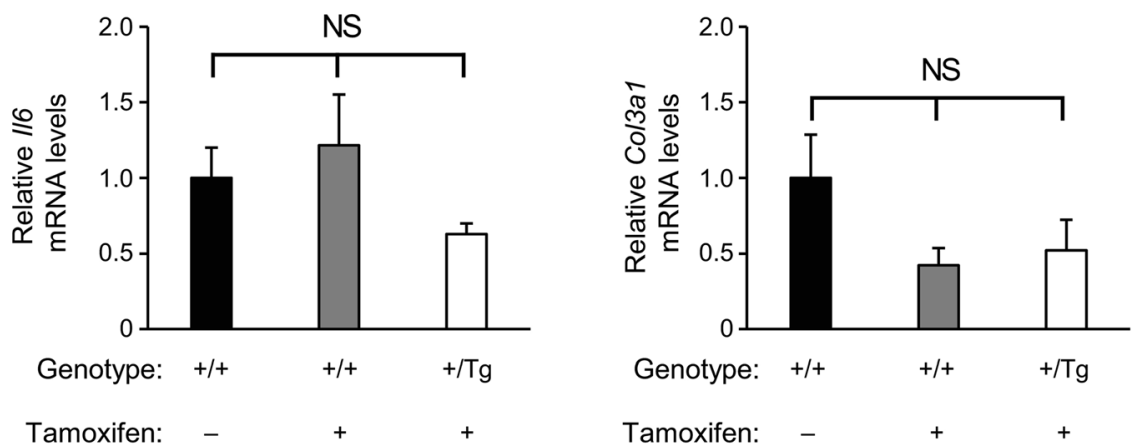

Fig. 5 Analysis of short-term treatment of tamoxifen on heart. a Strategies for treating adult VIPR2-ERT2CreERT2 ${ }^{\text {Tg/+ }}$ and wild-type mice with tamoxifen. $\mathbf{b}$ and $\mathbf{c}$ Total RNA prepared from each group of mice $(n=4)$ was analyzed by qRT-PCR. Relative $I I-6$ mRNA and Col3a1 mRNA levels in the heart were then compared. Data are presented as mean \pm SEM. NS, statistically insignificant, one-way ANOVA

\section{Conclusions}

LacZ staining after crossing with Rosa26-lacZ reporter mouse revealed that VIPR2-ERT2CreERT2 transgenic mice showed tamoxifen-dependent Cre activity only in the heart. This transgenic mouse can be used as a tool to temporally and spatially target genes in the heart and then, making it a useful model for revealing specific gene functions in the heart.

\section{Abbreviations}

CreERT2: Cre recombinase fused with a mutant form of estrogen receptor; E11.5: Embryonic day 11.5; ERT2: Mutant form of estrogen receptor; FACS: Fluorescence-activated cell sorting; H\&E: Hematoxylin and eosin Y; hCG: Human chorionic gonadotropin.; IACUC: Institutional Animal Care and Use Committee; Myh6: a-myosin heavy chain; qRT-PCR: Quantitative RT-PCR; RT: Reverse-transcription; VIPR2: Vasoactive intestinal peptide receptor 2

\section{Acknowledgments}

We thank Daekee's lab member for animal care and helpful discussion.

\section{Authors' contributions}

HJC, S-yL and DL designed research and performed experiments; HJC and $\mathrm{DL}$ analyzed data and wrote the manuscript. The author(s) read and approved the final manuscript.

\section{Funding}

This research was supported by a 2014 grant (14182MFDS978) from the Ministry of Food and Drug Safety, Republic of Korea.

\section{Availability of data and materials}

VIPR2-ERT2CreERT2-001 transgenic mouse was backcrossed with C57BL/6 J mice for 10 generations, and then deposited in the Korea National Institute of Food and Drug Safety Evaluation for distribution [Stock number, 18-NIFD S-M-ET-001; Stock name, B6.Cg-Tg (VIPR2-ERT2CreERT2) ${ }^{\text {Dkl/Korl]. }}$

\section{Competing interests}

The authors declare that there are no conflicts of interests.

Received: 23 June 2020 Accepted: 7 September 2020

Published online: 15 September 2020

\section{References}

1. Gittenberger-de Groot AC, Bartelings MM, Deruiter MC, Poelmann RE. Basics of cardiac development for the understanding of congenital heart malformations. Pediatr Res. 2005;57(2):169-76.

2. Copp AJ. Death before birth: clues from gene knockouts and mutations. Trends Genet. 1995;11(3):87-93.

3. Branda CS, Dymecki SM. Talking about a revolution: the impact of sitespecific recombinases on genetic analyses in mice. Dev Cell. 2004;6(1):7-28.

4. Kim H, Kim M, Im SK, Fang S. Mouse Cre-LoxP system: general principles to determine tissue-specific roles of target genes. Lab Anim Res. 2018;34(4): 147-59.

5. Doetschman T, Azhar M. Cardiac-specific inducible and conditional gene targeting in mice. Circ Res. 2012;110(11):1498-512.

6. Feil $R$, Wagner J, Metzger $D$, Chambon P. Regulation of Cre recombinase activity by mutated estrogen receptor ligand-binding domains. Biochem Biophys Res Commun. 1997;237(3):752-7.

7. Zhang Y, Riesterer C, Ayrall AM, Sablitzky F, Littlewood TD, Reth M. Inducible site-directed recombination in mouse embryonic stem cells. Nucleic Acids Res. 1996;24(4):543-8.

8. Casanova E, Fehsenfeld S, Lemberger T, Shimshek DR, Sprengel R, Mantamadiotis T. ER-based double iCre fusion protein allows partial recombination in forebrain. Genesis. 2002;34(3):208-14.

9. Visel A, Minovitsky S, Dubchak I, Pennacchio LA. VISTA enhancer browser--a database of tissue-specific human enhancers. Nucleic Acids Res. 2007; 35(Database issue):D88-92

10. Lee D, Pearsall RS, Das S, Dey SK, Godfrey VL, Threadgill DW. Epiregulin is not essential for development of intestinal tumors but is required for protection from intestinal damage. Mol Cell Biol. 2004;24(20):8907-16.

11. Kim K, Lee $H$, Threadgill DW, Lee D. Epiregulin-dependent amphiregulin expression and ERBB2 signaling are involved in luteinizing hormone- 
induced paracrine signaling pathways in mouse ovary. Biochem Biophys Res Commun. 2011;405(2):319-24.

12. Chen M, Lichtler AC, Sheu TJ, Xie C, Zhang X, O'Keefe RJ, et al. Generation of a transgenic mouse model with chondrocyte-specific and tamoxifeninducible expression of Cre recombinase. Genesis. 2007;45(1):44-50.

13. Kim K, Kim H, Lee D. Site-specific modification of genome with cellpermeable Cre fusion protein in preimplantation mouse embryo. Biochem Biophys Res Commun. 2009;388(1):122-6.

14. Soriano P. Generalized lacZ expression with the ROSA26 Cre reporter strain. Nat Genet. 1999;21 (1):70-1.

15. Banerjee I, Fuseler JW, Price RL, Borg TK, Baudino TA. Determination of cell types and numbers during cardiac development in the neonatal and adult rat and mouse. Am J Physiol Heart Circ Physiol. 2007;293(3):H1883-91.

16. Agah R, Frenkel PA, French BA, Michael LH, Overbeek PA, Schneider MD. Gene recombination in postmitotic cells. Targeted expression of Cre recombinase provokes cardiac-restricted, site-specific rearrangement in adult ventricular muscle in vivo. J Clin Invest. 1997;100(1):169-79.

17. Minamino T, Gaussin V, DeMayo FJ, Schneider MD. Inducible gene targeting in postnatal myocardium by cardiac-specific expression of a hormoneactivated Cre fusion protein. Circ Res. 2001;88(6):587-92.

18. Sohal DS, Nghiem M, Crackower MA, Witt SA, Kimball TR, Tymitz KM, et al. Temporally regulated and tissue-specific gene manipulations in the adult and embryonic heart using a tamoxifen-inducible Cre protein. Circ Res. 2001:89(1):20-5.

19. Bersell K, Choudhury S, Mollova M, Polizzotti BD, Ganapathy B, Walsh S, et al. Moderate and high amounts of tamoxifen in alphaMHC-MerCreMer mice induce a DNA damage response, leading to heart failure and death. Dis Model Mech. 2013;6(6):1459-69.

20. Lexow J, Poggioli T, Sarathchandra P, Santini MP, Rosenthal N. Cardiac fibrosis in mice expressing an inducible myocardial-specific Cre driver. Dis Model Mech. 2013;6(6):1470-6

21. Yan J, Zhang L, Sultana N, Park DS, Shekhar A, Bu L, et al. A murine Myh6MerCreMer Knock-in allele specifically mediates temporal genetic deletion in Cardiomyocytes after Tamoxifen induction. PLoS One. 2015;10(7): e0133472.

\section{Publisher's Note}

Springer Nature remains neutral with regard to jurisdictional claims in published maps and institutional affiliations.

Ready to submit your research? Choose BMC and benefit from:

- fast, convenient online submission

- thorough peer review by experienced researchers in your field

- rapid publication on acceptance

- support for research data, including large and complex data types

- gold Open Access which fosters wider collaboration and increased citations

- maximum visibility for your research: over $100 \mathrm{M}$ website views per year

At $\mathrm{BMC}$, research is always in progress.

Learn more biomedcentral.com/submissions 